\title{
¿Qué criterio de igualdad requiere una democracia deliberativa?*
}

\author{
JULio MONTERO \\ Facultad de Filosofía y Letras \\ Universidad de Buenos Aires \\ Consejo Nacional de Investigaciones Científicas y Técnicas (CONICET) \\ juliomontero@fibertel.com.ar
}

\begin{abstract}
Resumen: En este artículo me propongo establecer un criterio de igualdad adecuado para una democracia deliberativa. A tales efectos, comenzaré analizando la propuesta de Rawls y las críticas que Sen le dirige. Luego presentaré el principio de autonomía de Guariglia y expondré sus dificultades. Finalmente, utilizando la idea de "capacidad deliberativa" de Bohman, presentaré mi propio criterio de igualdad. De acuerdo con este principio, el estado debe garantizar a todo ciudadano un umbral mínimo de capacidades intelectuales y materiales que le permita incorporarse al debate público; sin embargo, una vez alcanzado este umbral, los ciudadanos mismos deben decidir qué concepción de la justicia económica y social es la más apropiada para su sociedad.

Palabras clave: inclusión, capacidad deliberativa, funcionamiento público, participación
\end{abstract}

\begin{abstract}
In this paper I will try to establish an accurate criterion of equality for a deliberative democracy. In order to achieve this, I will begin by analyzing Rawls' proposal and Sen's criticisms to it. I will then present Guariglia's Principle of Autonomy and I will expound its problems. Finally, using Bohman's idea of "deliberative capability", I will present my own criterion of equality. According to this principle, the state has to guarantee every citizen the minimum threshold of material and intellectual abilities that will allow him or her to take part in public deliberation. However, once this threshold is achieved, citizens themselves are the ones to decide which conception of economic and social justice is the most appropriate for their political community.

Key words: inclusion, deliberative capacity, public functioning, participation
\end{abstract}

Frente a quienes piensan que la vida política sólo puede consistir en una lucha por el poder entre bandos rivales que intentan imponer a los demás sus propios intereses, los teóricos de la democracia deliberativa sostienen que aun en una sociedad pluralista es posible alcanzar un entendimiento respecto del bien común, no al modo de una concepción omnicomprensiva o densa del bien que excluya otras alternativas, sino como el resultado siempre revisable de un acuerdo argumentativo entre los ciudadanos. ${ }^{1}$ En

\footnotetext{
*Este artículo fue elaborado como parte del proyecto de investigación UBACYT "Derechos humanos, democracia deliberativa y calidad de vida", bajo la dirección del doctor Osvaldo Guariglia y la codirección de la doctora Graciela Vidiella. Deseo agradecer especialmente a Osvaldo Guariglia y a Mariano Garreta Leclercq, así como a dos dictaminadores anónimos de Diánoia, sus valiosas observaciones y comentarios.

${ }^{1}$ La idea de bien común a la que se refieren las concepciones de la democracia deliberativa es radicalmente diferente de la idea de bien común invocada por la retórica política religiosa, nacionalista o populista. En todos estos casos, el bien común surge del interior de doctrinas
} 
efecto, las concepciones de la democracia deliberativa que se han desarrollado en las últimas tres décadas, especialmente en respuesta a las teorías que C.B. Macpherson denominó "democracias de mercado" y a las propuestas comunitaristas, presentan modelos normativos ideales que, sin embargo, pueden servirnos para organizar nuestras instituciones. Si bien estas teorías fueron diseñadas originalmente para aplicarlas en sociedades dotadas de una cultura pública democrática con varias décadas de desarrollo, resultan, a mi juicio, particularmente atractivas en las condiciones de las actuales sociedades latinoamericanas, en las cuales, como muestran los episodios recientemente vividos en varios países de la región, la corrupción y la lógica facciosa de las tradicionales clases gobernantes, por un lado, y la sistemática marginación de amplios sectores de la sociedad del foro político, por el otro, han conducido a persistentes crisis de representación o de legitimidad. Tras varias décadas de dictaduras militares, la ciudadanía de estos países parece concentrar todas sus exigencias en una única reivindicación, a saber, la radicalización y profundización de la democracia en el campo político y social y el abandono de cualquier intento de volver a transitar el oscuro camino de la supresión del Estado de derecho. En este contexto, las concepciones de la democracia deliberativa - centradas en la colaboración entre las diversas clases y sectores que componen una misma sociedad y en la necesidad de reflotar el ideal del autogobierno y la participación democrática por las vías que ofrecen las asociaciones libres de la sociedad civil, la prensa independiente, los múltiples círculos científicos, académicos y profesionales y la nueva cultura de los derechos humanos que brotó con todo su vigor tras la caída del socialismo real en Europa del Este- pueden ofrecernos una alternativa promisoria a las tradicionales concepciones de la democracia liberal.

Puesto que, de acuerdo con los filósofos de la democracia deliberativa, lo que nos conduce al bien común es el debate público, un rasgo compartido por todas estas concepciones es la tesis de que los asuntos políticos relevantes deben ser decididos mediante un intercambio reglado de razones a favor y en contra en el que todos los ciudadanos expongan y defiendan argumentativamente propuestas surgidas de sus propias necesidades. ${ }^{2}$ Sin embargo, dado que es necesario definir un conjunto de condiciones que el debate democrático debe satisfacer para ser imparcial, quienes defienden esta perspectiva se enfrentan a un serio dilema que puede formularse del

parcial o totalmente comprehensivas y se presenta como independiente del debate público. Por el contrario, el bien común al que alude la democracia deliberativa se obtiene sólo tras un intercambio de razones y opiniones mantenido en el foro público político, respetando las reglas de lo que Rawls ha llamado la "razón pública", las cuales excluyen la defensa puramente sectaria o corporativa de los propios valores e intereses. Cfr. Rawls 2000, pp. 131 ss., y Cohen 1999a.

${ }^{2}$ Cfr. Cohen 1999a, pp. 72-73; Bohman y Rehg 1999b, p. ix, y Guariglia 1996, p. 170. 
modo que sigue: por un lado, el ideal de la democracia deliberativa demanda que la totalidad de las normas públicas surja de un debate colectivo entre ciudadanos libres e iguales, pero, por el otro, la deliberación misma presupone ineludiblemente la vigencia plena de aquellas estipulaciones que configuran el marco en el que debe desarrollarse. ${ }^{3}$ En efecto, como se consigna reiteradamente en la bibliografía sobre el tema, sólo la participación efectiva de todos los implicados asegura la naturaleza verdaderamente pública de las decisiones adoptadas y, por consiguiente, su legitimidad. Por ello, Jack Knight y James Johnson señalan que la democracia deliberativa requiere que

los participantes en el proceso deliberativo puedan involucrarse en un proceso discursivo de argumentación y persuasión. La tarea de cualquier participante es desarrollar y comunicar razones para actuar que inclinarán a los demás a suscribir los resultados colectivos que éste prefiere. Si [el participante] no está en condiciones, por la razón que sea, de llevar a cabo esta tarea, no estará en condiciones de afectar el proceso de decisión colectiva. Como consecuencia de este fracaso, sus intereses y sus metas seguramente no serán tenidos en cuenta por el proceso democrático. (Knight y Johnson 1999, p. 292)

Por cierto, la forma más sutil, y, al mismo tiempo, más habitual de exclusión de la deliberación democrática, especialmente en los países del Tercer Mundo, es no disponer de los recursos intelectuales o materiales requeridos para identificar y defender argumentativamente las propias necesidades e intereses. La pregunta, por tanto, sería, ¿qué debe hacer una teoría de la democracia deliberativa frente a esta situación? O, dicho con otras palabras, ¿qué criterio de igualdad demanda una concepción de este tipo? En el presente trabajo defenderé un criterio de igualdad, al que denomino principio de inclusión democrática, que toma como punto de partida la idea de "funcionamiento público" formulada por James Bohman. A tales efectos, analizaré tres criterios de igualdad diseñados para concepciones de la democracia deliberativa que considero de especial interés: el de Carlos Nino, el de John Rawls y el de Osvaldo Guariglia, e intentaré mostrar las dificultades con que tropieza cada uno de ellos. Frente a estas alternativas, el principio de inclusión que sugiero proporciona un canon de igualdad política, sensible a las múltiples situaciones particulares de individuos y grupos, que pretende lograr la incorporación de todos los ciudadanos a la deliberación, más allá de las desigualdades de riqueza habituales en las sociedades capitalistas, y sin presuponer, empero, ninguna concepción específica de la justicia ni del bien.

\footnotetext{
${ }^{3}$ Cfr. Michelman 1999, p. 158, y Vidiella 2003, p. 26.
} 
Una primera respuesta que puede darse a la pregunta por el tipo de igualdad que una democracia deliberativa reclama consiste en sostener que, como la disparidad de capacidades intelectuales y de recursos económicos entre los miembros de una misma sociedad indefectiblemente distorsiona los resultados de la deliberación, es esencial incorporar a las precondiciones de ésta, no solamente los clásicos derechos civiles y políticos, sino también los derechos económicos y sociales, destinados a asegurar a todos los individuos una dotación de recursos que les permita vivir una vida digna de personas. Sin embargo, como señaló Nino hace ya una veintena de años, esta propuesta conlleva un serio problema, pues si todos estos derechos deben estar garantizados a priori, el espectro de asuntos que ha de ser resuelto por la deliberación democrática se ve drásticamente reducido. En sus propios términos:

si cubrimos todas estas condiciones para otorgar valor [...] a la democracia, quedan muy pocas cuestiones a ser resueltas por la democracia. La mayoría de las discusiones políticas consisten en la apropiada distribución de este tipo de recursos. [...] Aquí nos enfrentamos una vez más con el conflicto entre procedimiento y sustancia, y nos conducimos nuevamente hacia la paradoja de la superfluidad [del gobierno], en este caso, [del gobierno] democrático. (Nino 1997, p. 193)

Concretamente, el problema vislumbrado por Nino puede formularse del modo que sigue: ¿debe la democracia deliberativa promover un maximalismo de los derechos en virtud del cual se provea a toda persona tanto de las libertades como de los medios materiales requeridos para incorporarse al debate en pie de igualdad, afectando con ello la autonomía democrática? $¿ \mathrm{O}$, por el contrario, debe permitirse que dichas cuestiones sean resueltas por la deliberación pública, a riesgo de que las desigualdades de poder, riqueza o influencia incidan ilícitamente sobre los resultados de la discusión? Con vistas a evitar un estrechamiento excesivo de los temas abiertos al debate, Nino sostiene que no es necesario fortalecer al máximo las precondiciones de la deliberación y que, por consiguiente, un régimen democrático debe limitarse a garantizar los "derechos políticos activos y pasivos, la libertad de expresión, la prohibición contra agresiones y contra las restricciones a la libertad de movimiento"; en pocas palabrasa, los derechos individuales civiles y políticos, supeditando el reconocimiento de los derechos económicos y sociales al acuerdo discursivo alcanzado por las diversas tradiciones ideológicas que suscriben los ciudadanos en el foro público de una democracia deliberativa. ${ }^{4} \mathrm{El}$ controvertido supuesto en el que Nino se

${ }^{4}$ Cfr. Nino 1997, p. 275, y 1989b, pp. 110, 113, etcétera. 
basa para inclinarse por esta alternativa es que, una vez asegurados los derechos civiles y políticos, la democracia se moverá necesariamente hacia el fortalecimiento de sus propias condiciones de posibilidad, de modo que los derechos de bienestar se conquistarían en el propio debate mediante las elecciones periódicas, la progresiva formación de una phrónesis pública que pueda discernir lo que es el bien para la sociedad en su conjunto, el libre intercambio de opiniones y argumentos y la fuerza del mejor argumento.

Lo que, a mi modo de ver, torna esta propuesta difícilmente aceptable es que si las posibilidades de los ciudadanos de participar en el debate son pronunciadamente desiguales, los acuerdos cooperativos alcanzados en la arena pública tenderán inevitablemente a promover las metas y los planes de los sectores más aventajados. Naturalmente, no es ésta la situación de muchas de las democracias del Primer Mundo, como las de Europa occidental, en las cuales, debido a la existencia de una cultura cívica con varios siglos de desarrollo, aun los ciudadanos peor situados logran incorporarse con relativo éxito a la vida democrática, ya sea directa o indirectamente, a través de la representación de intereses que llevan a cabo los sindicatos, las uniones de trabajadores, las asociaciones libres de la sociedad civil y los partidos políticos. Sin embargo, en las sociedades subdesarrolladas, esta capacidad de todos sus miembros adultos de participar en el debate público no constituye una realidad histórica, sino más bien una idea regulativa a la que éstas deberían tratar de aproximarse. En efecto, en las incipientes democracias de los países de América Latina, África y Europa del Este, la carencia de los recursos materiales y cognitivos adecuados por parte del grueso de la población permitió la emergencia de nuevas oligarquías constituidas por sociedades sui generis selladas entre caudillos políticos, representantes del empresariado, propietarios de medios masivos de comunicación, emisarios de multinacionales, jefes de diversas mafias, etc. A causa de ello, y contra lo que esperaba Nino, un procedimiento democrático montado sobre la férrea garantía de los derechos humanos civiles y políticos que se desentienda completamente de cuestiones referidas a la igualdad acabará muy probablemente socavando sus propias bases sociales y, con ellas, sus pretensiones de legitimidad, tal y como está ocurriendo actualmente en amplias regiones del planeta.

III

Hasta donde alcanzo a ver, el fracaso de la solución postulada por Nino, más cercana al liberalismo tradicional, deja en evidencia que toda concepción de la democracia deliberativa debe asegurar necesariamente a sus miembros cierto grado de igualdad. La cuestión de cuál sea el tipo de igualdad que una democracia deliberativa requiere es, sin embargo, tema de aguda controversia. Una de las alternativas que ha suscitado mayor con- 
senso es la propuesta por Rawls, quien, en su primer principio de justicia, enfatiza la necesidad de garantizar el justo valor de las libertades políticas. ${ }^{5}$ De acuerdo con él, esta garantía implica que

el valor de las libertades políticas para todos los ciudadanos, con independencia de su posición económica o social, debe ser aproximadamente igual, o al menos lo suficientemente igual, en el sentido de que todos tengan una oportunidad equitativa de acceder a cargos públicos y de influir sobre los resultados de las decisiones políticas. ${ }^{6}$

Este principio se complementa, a su vez, mediante un segundo principio de justicia que exige (a) igualdad de oportunidades entre todos los ciudadanos para el acceso a cargos y posiciones, y (b) que las desigualdades económicas redunden en un mayor beneficio para los miembros menos aventajados de la sociedad. Así, a través de la combinación de estos dos principios y de la distribución de "bienes primarios" que éstos demandan, Rawls no sólo espera asegurar a todas las personas una dotación mínima de recursos que puedan utilizar para realizar sus planes de vida, sino también resolver el problema de la igualdad de condiciones para tener acceso al debate público y para participar en las deliberaciones en pie de igualdad en el foro político de una democracia constitucional. ${ }^{7}$ Sin embargo, durante las últimas décadas, la propuesta de Rawls ha suscitado una enorme gama de críticas, la más penetrante de las cuales fue reiterada por Amartya Sen en diversos trabajos. En términos generales, Sen sostiene que el problema con la solución de Rawls es que ésta no tiene en cuenta las desventajas de individuos que sufren algún tipo de discapacidad, o que, a causa de sus situaciones contextuales, sean éstas geográficas, sociales o biológicas, carecen de las habilidades necesarias para convertir su dotación de recursos en la libertad de elegir y realizar un plan de vida. Como consecuencia, la distribución de bienes primarios que Rawls propone sería perfectamente compatible con profundas desigualdades entre distintos individuos o grupos de la población en lo que concierne a su capacidad de elegir entre diversos "funcionamientos". En oposición a la propuesta de Rawls, Sen sostiene que

los reclamos individuales no deberían ser evaluados en términos de los recursos o bienes primarios que las personas respectivamente poseen, sino en términos de las libertades de las que realmente gozan para escoger entre distintas formas de vivir que podrían tener razones para valorar. Es esta libertad real la que es representada por la "capacidad" de la persona para alcanzar

\footnotetext{
${ }^{5}$ Rawls 1996, p. 6. Cfr. Rawls 2004, pp. 73 ss.

${ }^{6}$ Rawls 1996, p. 327. Agradezco los comentarios de un dictaminador anónimo de Diánoia y de Mariano Garreta Leclercq en relación con este punto.

${ }^{7}$ Cfr. Knight y Johnson 1999, p. 296.
} 
diversas combinaciones alternativas de funcionamientos, es decir, de acciones y estados. (Sen 1990, pp. 115-116)

A causa de esta insensibilidad ante las situaciones particulares, entre otras cosas, la perspectiva adoptada por Rawls no aporta, a mi juicio, una respuesta satisfactoria a la pregunta por el tipo de igualdad que una democracia deliberativa demanda. En efecto, la democratización y la progresiva incorporación de la totalidad de la ciudadanía a la deliberación democrática, principalmente en los países del Tercer Mundo, parece requerir una asistencia especial por parte del Estado a favor de aquellos sectores de la población que enfrentan mayores escollos para incorporarse al debate. Tal es el caso de los grupos que se han visto sumidos durante varias décadas en la pobreza o directamente en la marginación y que no poseen los recursos cognitivos necesarios para expresar sus reclamos de manera adecuada, de quienes habitan regiones geográficas que se ven privadas del acceso a los avances tecnológicos y a la información, de las comunidades indígenas o las minorías segregadas de la vida política que desconocen el lenguaje de los derechos en el que sus conciudadanos articulan sus demandas frente al Estado, de las mujeres que viven en sociedades tradicionales que obstaculizan su ingreso a la arena pública, etcétera.

En su obra Moralidad y en otros escritos anteriores y posteriores, Guariglia ha presentado un criterio de redistribución diseñado para una concepción deliberativa, al que denominó principio de autonomía. Este principio, que se presenta como el corolario de dos principios políticos previos, destinados (i) a resguardar a los individuos de interferencias violentas por parte de terceros y (ii) a preservar la igualdad formal entre los miembros de una misma sociedad, puede formularse así:

A fin de garantizar la defensa de los derechos que a cada miembro de la sociedad le confieren los principios de la libertad negativa y de la igualdad, todo miembro de la sociedad deberá tener iguales posibilidades para alcanzar una capacidad madura que le permita hacer uso de sus derechos y articular argumentativamente sus demandas (Guariglia 1996, p. 171, y 1992, p. 29). ${ }^{8}$

Según Guariglia, el criterio de justicia distributiva que de aquí se deriva se aproxima a la propuesta de Rawls, con la importante diferencia de que,

\footnotetext{
${ }^{8}$ Precisamente porque el desarrollo de las capacidades que el principio de autonomía pretende garantizar constituye una condición necesaria para concebir y realizar cualquier concepción de la buena vida, Guariglia sostiene que dicho principio no se deriva de ninguna concepción particular o sustantiva del bien, sino de una concepción del bien meramente formal. Para dejar este punto completamente en claro, Guariglia propone en trabajos posteriores la existencia de una distinción entre la "autonomía postulada", que se refiere a la capacidad que un agente tiene de escoger libre y reflexivamente un plan de vida, y la "autonomía realizada", que se vincula con una concepción no formal sino sustantiva de la buena vida, defendida por la tradición liberal (cfr. Guariglia 2001, pp. 96-121).
} 
tal y como pretende Sen, tiene en cuenta la enorme variabilidad de las situaciones personales. En efecto, de acuerdo con él, este principio explicita un ideal de equidad en virtud del cual la provisión de asistencia que en cada caso se requiera será determinada teniendo en cuenta la necesidad de compensar deficiencias o desventajas biológicas o de otra índole. El principio de autonomía constituye, por tanto, un "criterio flexible de equidad" que establece un "índice implícito de prioridades", el cual, entre normas que respeten por igual a los ciudadanos en su calidad de personas libres e iguales, favorecerá a aquella que promueva las condiciones para que el mayor número de personas alcance su propia "madurez" y logre un pleno desarrollo de sus facultades morales en su dos vertientes, la moral y la prudencial. ${ }^{9}$

Ahora bien, a pesar de que, según Guariglia, el canon de igualdad por él propuesto no depende de ninguna concepción particular del bien, ni tampoco de un modelo perfeccionista del florecimiento humano, ya que está basado simplemente en las condiciones de ejercicio de la razón práctica y en los niveles de capacidad y autorreflexión mínimos para que una persona pueda escoger, realizar y revisar sus propios proyectos existenciales, él mismo reconoce, sin embargo, que dicho canon incorpora el concepto de "verdadero interés" que toda persona ha de tener en cuanto tal "por encima de sus convicciones individuales", sean éstas cuales fueren. ${ }^{10}$ En palabras del autor, esto equivale a

explicitar la idea de "fin en sí mismo" que Kant utiliza como definición de "persona". Pues, lo que la regla expresa como un derecho, proviene del concepto de "interés primario" inherente al concepto de persona como tal. Este interés primario consiste en tener aseguradas iguales oportunidades para desarrollar aquellas mínimas capacidades físicas, psíquicas, cognitivas, morales y estéticas, que lo conviertan en un ser que se autodetermine maduramente. (Guariglia 1996, p. 172) ${ }^{11}$

La pregunta que inmediatamente surge en este punto es ésta: ¿puede una teoría de la democracia deliberativa establecer un criterio de igualdad basado en un ideal de autonomía o en una concepción de la persona y de los intereses primarios ligados a ella, que los propios participantes de la deliberación pública no podrían legítimamente cuestionar y que, para decirlo en términos de Habermas, les es impuesto "por encima de sus cabezas"? Puesto que el núcleo mismo de las concepciones de la democracia deliberativa consiste en sostener que la totalidad de los asuntos públicos deben ser decididos mediante un intercambio reglado de razones a favor y en contra en el

${ }^{9}$ Cfr. Guariglia 1996, pp. 172 y 218-229.

${ }^{10}$ Cfr. Guariglia 1992, p. 30, y 1996, pp. 174-175.

${ }^{11}$ Cfr. Guariglia 1992, p. 29. 
curso del propio debate, éstas deben limitarse, a mi entender, a determinar las condiciones procedimentales y sustantivas más elementales para que éste tenga lugar, dejando en manos de los participantes la tarea de decidir cuáles son los intereses básicos de una persona que debe proteger el Estado y qué valor se le concederá a ideas tales como la de autonomía, madurez o autenticidad a la hora de resolver los conflictos de intereses que pudieran suscitarse. Es por ello que, a mi juicio, el principio de autonomía elaborado por Guariglia tampoco constituye un criterio de igualdad completamente adecuado para una concepción de la democracia deliberativa.

A continuación deseo presentar un criterio de igualdad que rescate los aspectos positivos de la propuesta de Guariglia, pero que esté libre de las dificultades que he señalado. Para ello voy a exponer primero, en forma sucinta, algunos componentes centrales de la idea de una democracia deliberativa. El primero de ellos se refiere a las condiciones ideales que el debate público debe respetar, entre las cuales generalmente se señalan éstas:

a) Las deliberaciones se llevan a cabo a través de debates públicos, en los cuales todas las partes tienen las mismas posibilidades de realizar propuestas, recoger información y sostener sus argumentos. b) Todos los presuntamente involucrados por las consecuencias de las decisiones que se tomen tienen iguales posibilidades de acceso y participación en el debate. c) Los participantes están libres de coacciones, externas o internas, de modo que cada uno de ellos puede aportar a la discusión nuevos temas, informaciones o propuestas, sin que la distribución preexistente de poder y recursos influya en la inclusión, exclusión o distorsión de los nuevos aportes. d) Las deliberaciones están destinadas a lograr el consenso total, pero nada garantiza que éste se alcance. Por ello, las deliberaciones concluyen con una votación regida por la regla de la mayoría, que se considera suficiente para sancionar la opinión mayoritaria, la cual regirá provisoriamente hasta que una nueva mayoría logre convencer a los demás. e) Las deliberaciones políticas comprenden todas las materias que pueden ser reguladas en interés de todos, incluidas aquellas que las concepciones tradicionales consideran de naturaleza "privada". ${ }^{12}$

En efecto, el cumplimiento de estas reglas es lo que determina la corrección o incorrección procedimental en el trámite de discusión y aprobación de una norma pública, al menos en el ámbito del debate parlamentario. Ahora bien, puesto que el debate público está orientado a crear normas

${ }^{12}$ Cfr. Habermas 2000, p. 381; Guariglia 1996, pp. 215-216, y Nino 1989a, pp. 392-393. 
y leyes que obliguen coercitivamente a ciudadanos libres e iguales, estas condiciones puramente procedimentales de la deliberación deben complementarse mediante un criterio de legitimidad como el principio liberal de legitimidad propuesto por Rawls, en virtud del cual

nuestro ejercicio del poder político es adecuado y por tanto justificable sólo cuando éste se ejerce de acuerdo con una constitución cuyos elementos esenciales podría esperarse razonablemente que todos los ciudadanos los respalden a la luz de principios e ideales aceptables para ellos como razonables y racionales. (Rawls 1996, p. 217) ${ }^{13}$

Está claro que detrás de este principio de legitimidad subyace un "criterio de reciprocidad" que constriñe a los participantes del foro político a realizar propuestas que, a su juicio, podrían ser aceptadas por los demás como ciudadanos libres e iguales, y no como seres dominados, manipulados o sometidos a la presión de una situación política o social inferior, de modo que este principio garantiza que los resultados de la deliberación serán aceptables para ciudadanos que suscriben las más diversas doctrinas comprehensivas, siempre que éstas sean razonables.

Podemos retomar ahora nuestra cuestión central, referida al tipo de igualdad que una democracia deliberativa demanda. En relación con este asunto, Bohman ha desarrollado, a partir de la teoría de las funciones y las capacidades de Sen, el fructífero concepto de "capacidad deliberativa", el cual remite a la capacidad que las personas tienen para alcanzar un "funcionamiento público adecuado". A su vez, la noción de "funcionamiento público adecuado" designa:

(i) "la capacidad social de iniciar una deliberación pública sobre las propias preocupaciones", $\mathrm{y}$

(ii) la capacidad de influir efectivamente en la discusión. ${ }^{14}$

Por esta vía, la propuesta de Bohman permite establecer un "umbral mínimo para la igualdad política y el reconocimiento social", y, por consiguiente, un criterio destinado a detectar aquellas desigualdades de capacidad que resultan inaceptables en el contexto de una democracia deliberativa, tales como las que tienen lugar cuando un ciudadano o un grupo de ciudadanos son completamente incapaces de iniciar un debate público sobre sus necesidades, o cuando existen sectores de la población que tendrían buenas razones para creer que sus propuestas serán sistemáticamente ignoradas por los demás miembros de la sociedad. ${ }^{15}$ Como consecuencia,

${ }^{13}$ Cfr. Rawls 2000, p. 137.

${ }^{14}$ Bohman 1999, p. 333.

${ }^{15}$ Cfr. Bohman 1999, p. 345, y Knight y Johnson 1999, p. 300. 
Bohman afirma que "la democracia deliberativa debe satisfacer las demandas de igualdad relativas a la participación efectiva al menos hasta el punto en que ningún ciudadano sea tan pobre como para no poder influir en los resultados [del debate] o evitar la exclusión". ${ }^{16}$ La "igualdad política" a la que Bohman se refiere en este pasaje determina, entonces, la obligación por parte del Estado de proveer a todo ciudadano de ese umbral de capacidades mínimas que harán posible su incorporación a la vida pública. ${ }^{17}$ A su vez, lo que convierte a esta concepción de la igualdad política en un criterio especialmente exigente es que no solamente tiene en cuenta la necesidad de dotar a las personas de ciertos bienes básicos, sino que también considera el hecho de que la diversidad existente entre los seres humanos determina que diferentes individuos o grupos de la población dispondrán de una capacidad desigual para alcanzar, mediante la misma dotación de recursos, un nivel semejante de funcionamiento público. ${ }^{18}$ Es precisamente en vista de ello que Bohman propone que la "pobreza política" sea medida por la incapacidad de los ciudadanos para participar efectivamente en el proceso democrático, y no meramente por la carencia de ciertos bienes fundamentales. En sus propias palabras:

\begin{abstract}
Algunos ciudadanos, o más típicamente ciertos grupos de ciudadanos, pueden carecer de ciertas capacidades necesarias para hacer un uso efectivo de sus derechos y libertades [...]. En este caso, podemos decir que esos ciudadanos están políticamente empobrecidos. Dicho de manera positiva, esta igualdad no es igualdad de resultados, sino, más bien, de capacidad para hacer un uso efectivo de las propias oportunidades o para convertir los recursos deliberativos en una influencia efectiva en el proceso deliberativo. (Bohman 1999, pp. 331332)
\end{abstract}

Como se colige de lo anterior, un régimen político en el cual vastos sectores de la ciudadanía carecen de la capacidad necesaria para intervenir en la vida política y para resistir la presión de las elites dominantes, ya sea que ésta se dé mediante la amenaza solapada de represalias o mediante intentos de cooptación clientelista, no podría ser de ningún modo considerado como una verdadera democracia deliberativa, sino como la variante de una oligarquía plebiscitaria, o, directamente, como una dictadura hábilmente maquillada.

Como consecuencia, el criterio de igualdad que, a la luz de los aportes de Bohman, voy a proponer como el más adecuado para una concepción de la democracia deliberativa, al que designaré principio de inclusión democrática $[I]$, estipula que

\footnotetext{
${ }^{16}$ Knight y Johnson 1999, p. 330.

${ }^{17}$ Cfr. Bohman 1999, p. 340.

${ }^{18}$ Cfr. Bohman 1999, p. 322.
} 
[I] entre normas públicas alternativas que satisfagan por igual (a) las condiciones ideales de la deliberación y (b) el principio liberal de legitimidad u otro semejante, deben privilegiarse aquellas que, dentro de los límites impuestos por las circunstancias sociales y económicas vigentes, más y mejor promuevan, en sus consecuencias previsibles, el desarrollo de aquellas capacidades que permitan a todos los ciudadanos alcanzar un funcionamiento público adecuado.

En otros términos, si bien dos normas alternativas pueden ser igualmente correctas por respetar ambas las condiciones ideales de la deliberación y un principio de legitimidad públicamente aceptado que honre el criterio de reciprocidad, una de ellas puede resultar, empero, preferible respecto de la otra en la medida en que su aplicación muy probablemente conducirá a que los sectores tradicionalmente marginados de la vida pública adquieran los recursos económicos y las destrezas cognitivas, expresivas $\mathrm{y}$ argumentativas que les permitan incluirse en el proceso deliberativo. ${ }^{19}$ A pesar de que el principio [I] representa en cierta medida una regla destinada a regular la distribución de las condiciones materiales de bienestar, como vivienda adecuada, provisión de alimentos, educación, atención médica, seguro de desempleo, etc., para todos los potenciales participantes de la deliberación constituye, no obstante, un criterio abstracto que no permite especificar por sí solo (i) la cantidad mínima necesaria y la naturaleza exacta de los bienes que se requieren en cada caso particular, ni tampoco (ii) el grado en el que una sociedad debe, en un momento determinado, fomentar una inclusión masiva en el debate público a expensas de otros objetivos que, ante la presión de las circunstancias, pueden resultar prioritarios. En efecto, puesto que la cuestión de cuáles bienes y en qué proporción deben ser distribuidos variará según (i) cada especie de sujetos, sus necesidades y sus capacidades, y (ii) según los recursos de los que una sociedad dispone, la aplicación del principio de inclusión $[I]$ se mantiene sujeta, al igual que el principio de autonomía defendido por Guariglia, al juego de las instituciones democráticas a las cuales provee de una guía para su desempeño. ${ }^{20}$ De este modo, el principio $[I]$ constituye un criterio flexible de preferibilidad entre normas y programas políticos rivales procedimentalmente correctos, que tendrá en cuenta, por un lado, las diferentes aptitudes que las personas tienen, con base en sus situaciones históricas, sociales, económicas, biológicas y psicológicas, para convertir sus recursos en la capacidad efectiva de iniciar procesos deliberativos y de influir en la discusión de acuerdo con sus propias necesidades, y, por el otro, las condiciones particulares por las que atraviesa una sociedad en un momento determinado; por ejemplo, severas crisis políticas y fiscales,

${ }^{19}$ Cfr. Guariglia 1996, p. 218.

${ }^{20}$ Cfr. Guariglia 2001, p. 136. 
guerras, catástrofes naturales, situaciones de emergencia social, periodos de reestructuración del Estado, o épocas de florecimiento y de expansión económica. ${ }^{21}$

La pregunta, sin embargo, sería: la postulación de este principio de inclusión ¿no implica, como temía Nino, una implementación paternalista de derechos y de planes políticos sobre los cuales la propia discusión colectiva debería pronunciarse? Si bien es cierto que el principio $[I]$ apunta a conseguir una redistribución de bienes y recursos que probablemente forzaría un mayor reconocimiento de los derechos económicos y sociales de las personas, su objetivo no es proveer de un criterio redistributivo general, ligado, por ejemplo, al supuesto interés primario que toda persona en cuanto tal tendría en poder "autodeterminarse maduramente", tal y como ocurre con el principio de autonomía, ni tampoco imponer una concepción particular de lo que es una sociedad justa. Por cierto, hasta donde alcanzo a ver, el asegurar a todos los miembros de una sociedad la capacidad de alcanzar un funcionamiento público adecuado es compatible, prima facie, con un amplísimo rango de programas políticos y económicos, tanto progresistas como conservadores. ${ }^{22}$ En este sentido, los ciudadanos mismos son quienes, una vez superado el umbral de la "igualdad política", para decirlo en términos de Bohman, deberán decidir, mediante un intercambio de razones siempre sujeto a revisión, si adoptarán modelos económicos que procuren atenuar las diferencias de riqueza, haciendo más iguales a los desiguales, o si, por el contrario, éstas tendrán que ser toleradas como el resultado inevitable de la desigualdad de talentos naturales o de decisiones de vida llevadas a cabo de manera responsable y consciente por las personas. Al mismo tiempo, cuáles sean los medios más adecuados para superar la pobreza política, cómo deban distribuirse las cargas que dicho esfuerzo conlleva, o qué objetivos haya que privilegiar en diversos escenarios económicos, políticos y sociales, domésticos o globales, son cuestiones por resolver en un foro democrático en el que no se impone a los ciudadanos ninguna concep-

\footnotetext{
${ }^{21}$ Probablemente sería razonable que estados que, como los de Asia y África recientemente afectados por un maremoto de dimensiones colosales, enfrenten una situación de emergencia, decidan no desviar parte de su presupuesto a promover la inclusión en el debate público y prefieran concentrar todos los recursos disponibles en asistir a las víctimas de una catástrofe semejante. Lo mismo podría decirse, quizás, de aquellos países del África central que se ven afectados por hambrunas, epidemias, elevadas tasas de mortalidad infantil, etcétera.

${ }^{22}$ En efecto, a mi modo de ver, un Estado puede garantizar a sus ciudadanos un funcionamiento público adecuado aun cuando tolere la existencia de cierto grado de desigualdad en el poder adquisitivo de sus habitantes, un nivel relativamente alto de concentración de capitales productivos y financieros, un ordenamiento privado del sistema de salud o del sistema de previsión social y muchas otras propuestas impulsadas actualmente por la tendencia de centro derecha en el marco del mundo occidental, aunque no todas ellas. En este sentido, creo que una de las principales ventajas de mi propuesta respecto de las de Guariglia y Rawls es que su justificación normativa se mantiene en un terreno neutral entre el liberalismo igualitario y el liberalismo conservador o libertarianismo.
} 
ción particular, sustantiva o formal, del bien y en el que ninguna propuesta queda excluida a priori. $^{23}$

\section{V}

Ahora bien, el problema evidente que surge con un principio como $[I]$ es que, al supeditar las demandas relativas a la obtención de la capacidad necesaria para lograr una inclusión efectiva en el proceso de deliberación al acuerdo parlamentario y al propio debate público, las mismas desigualdades de partida que hicieron necesaria su introducción podrían impedir a los ciudadanos políticamente empobrecidos desafiar las concepciones de la igualdad política imperantes e imponer argumentativamente aquellas propuestas que tenderían a que todos los implicados potenciales alcanzaran un funcionamiento público adecuado. ${ }^{24}$ Dado que lo que caracteriza a una concepción radical de la democracia como la que aquí estamos proponiendo es, empero, la exigencia de que todas las decisiones políticas sean antecedidas por el paso previo de la deliberación en común, existe, a mi modo de ver, una sola manera de resolver esta dificultad sin incurrir en alternativas autoritarias que intenten imponer un único modelo posible de sociedad justa dogmáticamente cerrado a la crítica y a la discusión pública. Esta solución consiste en complementar el principio de inclusión [I] con el siguiente deber moral, que constriñe el comportamiento de aquellos ciudadanos que, dada su situación económica y social, pueden acceder a la deliberación y a la esfera del espacio público en la que se conforman las corrientes de opinión política que condicionan la toma de decisiones en el nivel del parlamento, y, en menor medida, del poder ejecutivo y judicial. Este deber establece que

[i] aquellos ciudadanos que puedan participar de la deliberación democrática y que puedan contribuir a la conformación de la opinión pública, incluyendo especialmente a los miembros de los tres poderes del Estado, a los representantes de los partidos políticos, a los responsables de los medios de comunicación y a los activistas y militantes políticos y de organizaciones no gubernamentales, deben promover el cumplimiento del principio de inclusión [I].

Claramente, la enorme desigualdad de hecho que en lo concerniente a capacidad deliberativa existe en gran parte de las democracias subdesarrolladas actuales obliga a una representación de intereses en la que, como sostiene Guariglia, es necesario cierto "tutelaje" de los sectores con mayor formación cívica y vocación democrática, orientada a que todos los ciudadanos desarrollen las aptitudes que les permitan incluirse en el proceso

${ }^{23}$ Cfr. Nussbaum 2002, pp. 143-144.

${ }^{24}$ Cfr. Vidiella y Bertomeu 2000, p. 304. 
deliberativo y defender autónomamente sus propuestas. ${ }^{25}$ En este papel de tutelaje es central, a mi juicio, el aporte de los grupos de intelectuales, de los activistas políticos y de derechos humanos, de las asociaciones de trabajadores y profesionales, de un periodismo ilustrado e independiente, $\mathrm{y}$, fundamentalmente, de las nuevas organizaciones no gubernamentales, que han comenzado a formar un cinturón cada vez más denso en torno a las instituciones democráticas, al menos en el mundo occidental. Precisamente en esta dirección, Joshua Cohen señala que "más allá del mundo de los votantes y los partidos, las asociaciones secundarias - grupos organizados intermedios entre el mercado y el Estado- son necesarias, tanto para representar intereses de otro modo carentes de representación [...], como para contribuir a alcanzar la perspectiva del bien común" (Cohen 1999b, p. 426). En efecto, el hecho de que la historia de la democratización muestre que los mayores logros en lo concerniente a la inclusión en el debate público han surgido usualmente de la presión que sobre el Estado ejercieron grupos y movimientos organizados en el ámbito de la sociedad civil, permite suponer que sólo con base en el compromiso moral de ciudadanos dotados de un espíritu democrático activo se pueden generar aquellos engranajes institucionales que permitan realizar la utopía de la inclusión plena. ${ }^{26}$ A su vez, esta inclusión progresiva de los ciudadanos en la vida pública, que trasciende las barreras de clase, las diferencias étnicas, culturales y de género, los localismos, etc., es el único camino del que, en mi opinión, disponemos para edificar una verdadera democracia deliberativa a largo plazo, pues cuantos más sean los ciudadanos que puedan tener acceso al debate, tanto mayor será la transparencia del manejo de los asuntos del Estado y el carácter público de las decisiones adoptadas. Como consecuencia de ello, las oligarquías políticas fundadas sobre la concesión de prebendas, el nepotismo y el clientelismo, el manejo monopólico de los medios masivos de comunicación, las sociedades formadas entre mafias de diversa índole y la clase gobernante, y los actos de corrupción, que son moneda corriente en las democracias subdesarrolladas, irán cediendo terreno ante una ciudadanía dispuesta a darse a sí misma su propia ley por el camino de la deliberación en común.

\section{BIBLIOGRAFÍA}

Bohman, James, 1999, "Deliberative Democracy and Effective Social Freedom: Capabilities, Resources, and Opportunities", en Bohman y Rehg 1999a, pp. 321349.

${ }^{25}$ Cfr. Guariglia 1996, p. 175, y Cohen 1999b, p. 427.

${ }^{26}$ Cfr. Dryzek 2002, pp. 86, 104, etcétera. 
Bohman, James y William Rehg (comps.), 1999a, Deliberative Democracy. Essays on Reason and Politics, The MIT Press, Cambridge, Mass.

Bohman, James y William Rehg, 1999b, "Introduction", en Bohman y Rehg 1999a, pp. ix-xxx.

Cohen, Joshua, 1999a, "Deliberation and Democratic Legitimacy", en Bohman y Rehg 1999a, pp. 67-93.

_, $1999 \mathrm{~b}$, "Procedure and Substance in Deliberative Democracy", en Bohman y Rehg 1999a, pp. 407-439.

Dryzek, John, 2002, Deliberative Democracy and Beyond, Oxford University Press, Oxford.

Guariglia, Osvaldo, inédito, "Social and Economic Human Rights as a Way to Impede Corruption".

— , 2001, Una ética para el siglo XXI. Ética y derechos humanos en un mundo posmetafísico, Fondo de Cultura Económica, Buenos Aires.

— 1996, Moralidad. Ética universalista y sujeto moral, Fondo de Cultura Económica, Buenos Aires.

__ 1992, "El concepto normativo de 'persona' y los requisitos mínimos de justicia distributiva en una sociedad democrática", Desarrollo Económico. Revista de Ciencias Sociales (Instituto de Desarrollo Económico y Social), vol. 32, no. 125, pp. 23-33.

Habermas, Jürgen, 2000, Facticidad y validez. Sobre el derecho y el Estado democrático de derecho en términos de teoría del discurso, trad. Manuel Jiménez Redondo, Trotta, Madrid.

Knight, Jack y James Johnson, 1999, "What Sort of Equality Does Deliberative Democracy Require?”, en Bohman y Rehg 1999a, pp. 279-321.

Michelman, Frank, 1999, "How Can the Peolple Ever Make the Laws? A Critique of Deliberative Democracy", en Bohman y Rehg 1999a, pp. 145-173.

Nino, Carlos, 1997, La constitución de la democracia deliberativa, Gedisa, Buenos Aires.

—_, 1989a, Ética y derechos humanos, Astrea, Buenos Aires.

$\longrightarrow, 1989 \mathrm{~b}$, El constructivismo ético, Centro de Estudios Constitucionales, Madrid.

Nussbaum, Martha, 2002, "Capabilities and Human Rights", en Pablo De Greiff y C. Cronin, Global Justice and Transnational Politics. Essays on the Moral and Political Challenges of Globalization, The MIT Press, Cambridge, Mass., pp. 117151.

Rawls, John, 2004, La justicia como equidad: una reformulación, trad. Andrés de Francisco, Paidós, Buenos Aires.

— 2 2000, The Law of Peoples with "The Idea of Public Reason Revisited", Harvard University Press, Cambridge, Mass. [Versión en castellano: El derecho de gentes y una revisión de "La idea de razón pública", trad. Hernando Valencia Villa, Paidós, Barcelona, 2001.]

—_, 1996, Political Liberalism, Columbia University Press, Nueva York. [Versión en castellano: El liberalismo político, trad. Antoni Demoenech, Crítica, Barcelona, 1996.]

Sen, Amartya, 1990, “Justice Means versus Freedom”, Journal of Philosophy, no. 82, pp. 169-121. 
Vidiella, Graciela, 2003, "La razón pública y la democracia deliberativa", Phrónesis. Revista de Filosofía y Cultura Democrática, no. 10, abril de 2003, pp. 26-28.

Vidiella, Graciela y María Julia Bertomeu, 2000, "Democracia, justicia y concepciones del bien. (Algunos puntos en discusión)", en M.J. Bertomeu, R. Gaeta y G. Vidiella, Universalismo y multiculturalismo, Eudeba, Buenos Aires, pp. 297304.

Recibido el 4 de febrero de 2005; aceptado el 3 de mayo de 2005. 